Wolfgang Merbach, Annette Deubel

The Long-Term Fertilization Trials in Halle (Saale), Germany 


\section{TEUBNER RESEARCH}


Wolfgang Merbach, Annette Deubel

\section{The Long-Term Fertilization Trials in Halle (Saale), Germany}

A Tool for Sustainable and Environmentally Compatible Land Management Contributions of Plant Nutrition Science in Halle 13

2nd revised Edition 
Bibliographic information published by Die Deutsche Nationalbibliothek

Die Deutsche Nationalbibliothek lists this publication in the Deutsche Nationalbibliografie; detailed bibliographic data is available in the Internet at <http://dnb.d-nb.de $>$.

2nd revised Edition July 2007

All rights reserved

(C) Deutscher Universitäts-Verlag I GWV Fachverlage GmbH, Wiesbaden 2007

Readers: Frauke Schindler / Anita Wilke

Deutscher Universitäts-Verlag and Teubner Verlag are companies of

Springer Science+Business Media.

www.duv.de

www.teubner.de

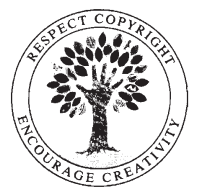

No part of this publication may be reproduced, stored in a retrieval system or transmitted, mechanical, photocopying or otherwise without prior permission of the copyright holder.

Registered and/or industrial names, trade names, trade descriptions etc. cited in this publication are part of the law for trade-mark protection and may not be used free in any form or by any means even if this is not specifically marked.

Cover design: Regine Zimmer, Dipl.-Designerin, Frankfurt/Main

Printed on acid-free paper

Printed in Germany

ISBN 978-3-8350-4000-7 


\section{Preface}

The soils of our planet in enabling and sustaining plant growth provide the basis of human existence, as about $98 \%$ of all foodstuff is primarily produced by terrestrial ecosystems. As a consequence of erosion, desertification, and the development of buildings, roads, industrial estates, etc, the utilizable soil surface area of the world is now decreasing by about 10 million ha annually, a loss which is occurring concurrently with a rapid increase of world population which is expected to reach 8.5 billion people by the year 2020. A diminishing soil area has thus to satisfy an ever increasing population. The human race is therefore faced with the major challenge of ensuring substantial and rising increases in plant production per unit land area worldwide, but with lower resource inputs and the need for long-term preservation of soil fertility under uncertain and possibly strongly changing climatic conditions on a global scale.

Scientifically sound recommendations for agricultural and environmental policies are expected from research work. These require well-founded knowledge about the reaction of soils and agroecosystems towards different cultivation and fertilization practices as well as towards climatic factors. Such knowledge can only be obtained by long-term investigations, as the effects of human activity as well as of non-anthropogenic factors occur very gradually because of the buffer capacity of the ecosystems, and they are often quantifiable only in the fullness of time. Long-term field experiments carried out under different soil and climatic conditions provide a unique possibility for the recognition and documentation of such long-term changes in the soils and plants of a specific site as affected by different fertilization and cultivation treatments, side by side.

Such long term changes may include the duration and extent of nutrient delivery potentials, the duration and the level of adjustment to new steady states in nutrient or carbon dynamics, or the course of soil development processes. Thus, recommendations and the development of concepts for achieving sustainable soil usage and long-term maintenance of soil fertility are based on the results of longterm trials, which represent the most important soil, climate and cultivation conditions on earth. Unfortunately a comprehensive representing of these conditions is no longer the case nowadays. For instance in Germany various long-term experiments have been discontinued over the past years on grounds of technical and financial reasons, e.g. this also included the formerly oldest German long-term trial, the Göttinger E-Field. The continuation of other important long-term trials, 
as e.g. the Eternal Rye in Halle and the Static Fertilization Trial in Bad Lauchstädt are also endangered for financial reasons. Presently there are only about 65 experiments worldwide which have been running for more than 50 years.

In 1997 therefore a memorandum of the International Conference in Berlin on the occasion of the 60 years` duration of the Thyrower long-term trials noted the importance of such experiments (AUTORENKOLLEKTIV 1997); more recently the value of the European long-term experiments for a sustainable and ecologically beneficial land management has been recorded by the senate committee for "Substances and Resources in the Agriculture" of the German Research Foundation (DFG (FREDE et al. 2006).

The present book will contribute to this aim. It introduces the results of the longterm fertilization trials in Halle obtained so far. These include the Eternal Rye trial (Ewiger Roggenbau), laid out by Julius KÜHN in 1878, and the long-term fertilization trials started by Karl SCHMALFUB in 1949. Besides the Wheat Experiment in Rothamsted (England) and the Static Fertilization Trial in Bad Lauchstädt (Germany), these experiments at the Martin-Luther-University HalleWittenberg are the most important long-term fertilization trials worldwide, and must in the future be used to the best advantage.

The authors are grateful to Prof. Dr. J. Garz, Dozent Dr. L. Schmidt, Prof. Dr. P. Pickel, Dr. U. Klee and Prof. Dr. E. Weber for their scientific advice and for allowing us to use their experimental data. Thanks are also due to Dipl.-Ing. Th. CHudy (Halle) for the consultation in location problems, Dr. Birgit W. Hütsch (Wetzlar) for the translation into English, Mr. Ernest A. Kirkby, University of Leeds, UK for improving the English text, and Mrs. M. Petzold (Halle) for technical work.

Halle, in March 2007

Wolfgang Merbach Annette Deubel 


\section{Contents}

1 Site and Surroundings - the Julius-Kühn-Field in Halle …................................. 1

1.1 The Geographical Position .................................................................................................... 1

1.2 The Natural Site Conditions ……......................................................................... 3

1.2.1 The Climate .............................................................................................. 3

1.2.2 The Natural Conditions ……..................................................................................... 6

1.2.3 The Soil .......................................................................................................... 6

1.3 The Development of the Julius-Kühn-Field since its Foundation in the Year 1866 ..................................................................................................................... 11

1.3.1 Regional and Administrative Development ................................................. 11

1.3.2 Previous Scientific Development of the Julius-Kühn-Field ……........ 13

1.4 Present Scope of Duties of the Julius-Kühn-Field ............................................. 17

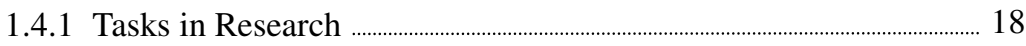

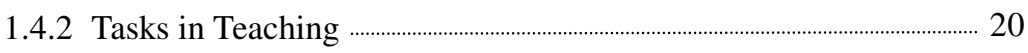

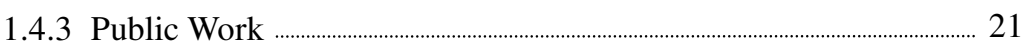

2 The Long-Term Fertilization Trials at the Julius-Kühn-Field in

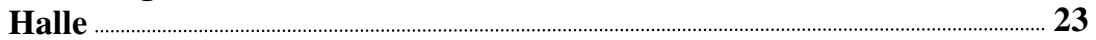

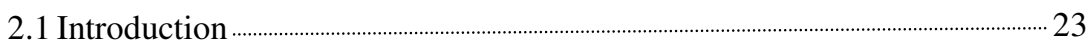

2.2 The Eternal Rye Trial, started in 1878 ........................................................................... 24

2.3 The Long-Term Fertilization Trials started in 1949........................................... 45

2.3.1 General aspects ........................................................................................ 45

2.3.2 The Lime Fertilization Trial (Field A) ........................................................ 48

2.3.3 Trial on the Physiological Reaction of Fertilizers (Field B) ….............. 56

2.3.4 The Potassium Fertilization Trial (Field $C$ ).................................................. 58

2.3.5 The Phosphate Fertilization Trial (Field D) .................................................. 70

2.3.6 The Nitrogen Fertilization Trial (Field E) …………................................ 78

2.3.7 The Organic-Mineral Fertilization Trial (Field F) ……........................... 81

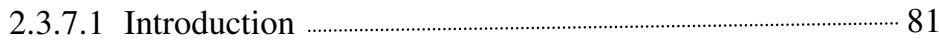

2.3.7.2 The Nutrient Deficiency Trial (Field F1a) ……....................... 84 
2.3.7.3 Farmyard Manure and Mineral Fertilization

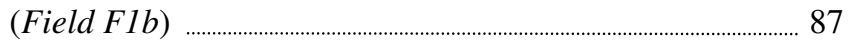

2.3.7.4 Straw Application Every Year (Field F2a) ….......................... 91

2.3.7.5 Straw Fertilization Every Second Year (Field F2b) ............. 96

2.3.7.6 Farmyard Manure, Humus and Yield (Field F3) .................... 99

3 The Soil Development Trial started in 1948 (Halle, Adam-

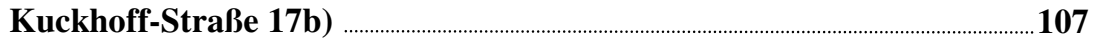

3.1 Experimental Set-up and Cultivation of Crops .......................................................... 107

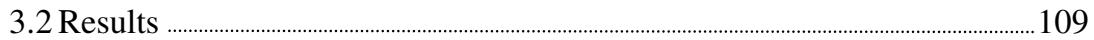

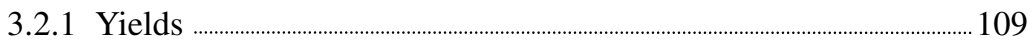

3.2.2 Soil Organic Matter ….............................................................................................. 110

3.2.2.1 C and N Contents ............................................................................ 110

3.2.2.2 Humification ................................................................................................. 113

3.2.2.3 Microbial Biomass .................................................................................... 115

3.2.3 Nutrient Dynamics ............................................................................................ 116

3.2.3.1 Nitrogen Dynamics .............................................................................. 116

3.2.3.2 Phosphorus Dynamics ....................................................................... 117

3.2.3.3 Potassium Dynamics................................................................................ 120

3.2.3.4 Lime Content and Cation Exchange Capacity ....................... 120

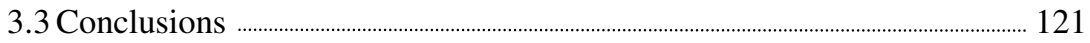

4 Final Remarks and Approaches to Continue the Long-Term

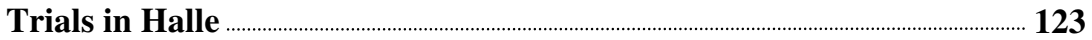

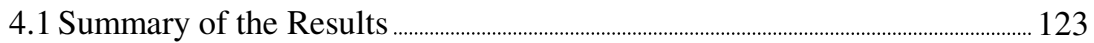

4.2 Importance and Scope of the Long-Term Fertilization Trials in

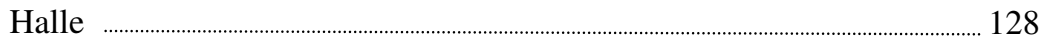

4.2.1 General Importance of Long-Term Trials ...................................................... 128

4.2.2 Importance and Special Features of the Long-Term Fertilization Trials in Halle

4.3 Approaches to Continue the Long-Term Fertilization Trials in Halle

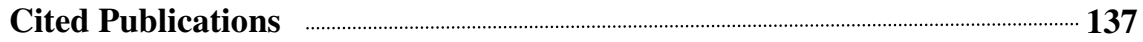

Publications about the Long-Term Fertilization Trials in Halle 